\title{
Chronic Kidney Disease Awareness in the Population of Moderate and High Cardiovascular Risk
}

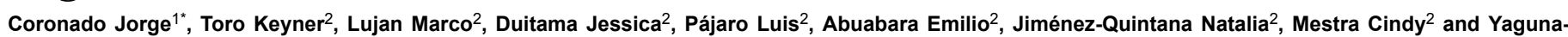
Guerra José $^{2}$

${ }^{1}$ Internal Medicine and Nephrology, University of Cartagena, Colombia

${ }^{2}$ School of Medicine, University of Cartagena, Colombia

*Corresponding author: Coronado Jorge, Internal Medicine and Nephrology, University of Cartagena, Colombia, Tel: +573145240109; E-mail: jcoronadod@unicartagena.edu.co; jocodada@yahoo.es

Received date: October 22, 2016; Accepted date: October 29, 2016; Published date: October 31, 2016

Copyright: (c) 2016 Jorge C, et al. This is an open-access article distributed under the terms of the Creative Commons Attribution License; which permits unrestricted use; distribution; and reproduction in any medium; provided the original author and source are credited.

\begin{abstract}
Background: Among the recommendations for the prevention of high cardiovascular morbidity and mortality in patients with chronic kidney disease (CKD) enhanced surveillance, detection and awareness of this condition include; which are mainly targeting populations with increased risk. Yet despite a high prevalence of CKD in these patients, there is limited knowledge of the disease in populations at high cardiovascular risk, especially in developing countries. To determine the awareness of CKD in the population of moderate and high cardiovascular risk.
\end{abstract}

Methods: A prevalence study, multicenter was developed; the sample corresponds to adults over 18 with moderate or high cardiovascular risk (defined as Framingham criteria), treated at the outpatient clinic for health institutions in the city of Cartagena from April 2013 to October 2014.

Statistical analysis: descriptive univariate and bivariate analyzes were performed using measures of central tendency and dispersion for continuous variables and proportions for qualitative variables. The association between variables was established by The Chi square test and Fisher's exact test.

Results: 653 patients were included, the prevalence of CKD was $34.8 \%$ and overall awareness of it was $70.9 \%$ and $48.2 \%$ by the health system and the patient respectively. There was no association between awareness of CKD both the health system and the patient and the level of cardiovascular risk ( $p=0.916$ and $p=0.772$ ). In unconscious patients with CKD have a higher proportion of women compared with patients with CKD awareness $(95 \% \mathrm{Cl}$ for the difference, 4.3 to $29.766 .1 \%$ vs $49.1 \%$ ) was found. There was a significant association between CKD awareness, adherence to lifestyle $(p \leq 0.0001)$ and medication adherence $(p=0.041)$, was determined that unconscious patients had lower compliance healthy lifestyles $(22,9 \%$ vs $64.5 \% ; 95 \% \mathrm{Cl}$ for the difference, 29.9 to 53.3$)$ and pharmacological (92.4\% vs $98.2 \% ; 95 \% \mathrm{Cl}$ for the difference, 2.7 to 11.3 ) than patients aware for the disease.

Conclusions: This study demonstrates the high prevalence of CKD in patients with moderate and high cardiovascular risk, highlighting the inadequate consciousness we have of it in this population.

Keywords: Awareness; Chronic kidney disease; Cardiovascular risk

\section{Introduction}

For 2008 it is estimated that there were 57 million deaths worldwide, of which $63 \%$ (36 million) were due to non-communicable chronic diseases (NCD) [1]. The chronic kidney disease (CKD) is a key determinant of poor health outcomes result of major NCD because it is associated with a threshold of eight to ten times increase in mortality cardiovascular [2-4].

Inside the NCD the cardiovascular diseases undoubtedly have the major impact, which as well as worldwide are the leading cause of death in Latin America and Colombia [4]. This is why the different scientific societies in their desire to prevent atherosclerosis, fundamental cause of the cardiovascular disease, and given its multifactorial origin, recommend the estimation of the cardiovascular global risk (using tables as the Framingham) to classify the people under the different groups at risk, on the basis of being able to prioritize the different interventions to prevent cardiovascular events [5].

Regarding CKD, the fact that the measure of the Glomerular Filtration Rate -GFR (main criterion used for diagnosis and classification of CKD) in a direct way is expensive and complex has led to the use of various methods of calculation estimated glomerular filtration rate (eGFR) derived from the serum creatinine concentration. In our country, the data on the national registry for CKD of the high cost account are based on eGFR according to the equation of Cockcroft-Gault (CG) that as we know in the light of the current evidence is less precise than his more recent counterparts, Modification of Diet in Renal Disease (MDRD) equation and Chronic Kidney Disease Epidemiology Collaboration (CKD-EPI) equation [6-9]. These are more accurate to eGFR greater than $60 \mathrm{ml} / \mathrm{min} / 1.73$ $\mathrm{m}^{2}$ and still do not have validation studies in Colombia, like the CG equation. 
The adoption of international guidelines for the diagnosis and classification for CKD K/DIGO (Kidney Disease Improving Global Outcomes) has led to better detection of this disease [10]. However, despite high prevalence rates of the disease its awareness rates (defined as the percentage of people who have been diagnosed with CKD by evidence of kidney damage or kidney failure through regular examinations by their treating physicians in health institutions but cannot understand their diagnosis and thus recognize the importance of treatment) are still low, with only a quarter of individuals with chronic kidney disease knowing the poor state of their renal function in the best case scenario $[11,12]$.

There is no doubt that better management of the CKD can delay the progression of it, prevent cardiovascular complications and reduce related outcomes, but although efforts to improve quality are universally accepted by the medical community, patients should seek prompt treatment once they are aware of their status to be exposed to such initiatives [13]. This problem is more pronounced in developing nations where knowledge of CKD by health personnel is significantly lower (lack of awareness by caregivers as defined by eGFR patient qualifies for CKD but has not made a diagnosis as such by part of your physician), which probably served as a barrier to access to appropriate care, even when it becomes available [14].

Our primary objective was to determine the rate of awareness of $\mathrm{CKD}$ in patients with moderate and high cardiovascular risk in addition to characterize the variables and the degree of control of the most common diseases associated with this condition, determining as well if there's an association between this awareness for the disease and adherence to established outpatient care.

\section{Materials and Methods}

\section{Study design and population}

A prevalence study, multicenter, whose protocol was approved by an institutional review board that covered the population of cardiovascular risk and consulted different companies that are promoters of health (EPS), both subsidized and contributive of the General System of Social Security in Health (SGSSS) of Colombia since April 2013 to October 2014 with headquarters in the city of Cartagena and that met the selection criteria to be adults (older than 18 yearsold) with a risk of cardiovascular event $>10 \%$ at 10 years according to Framingham score. We excluded patients with predisposing conditions defined GFR decreased temporarily as diarrhea, vomiting, bleeding, recent hospitalization or urinary obstruction. We also excluded patients in which the value of serum creatinine did not represent a reliable marker for calculate eGFR (amputees patients, vegetarians, paraplegics).

\section{Sample size}

It was take into account that the population between 20 and 75 years in Cartagena is $58,6 \%$ and as calculated by the district administrative department of health (DADIS) for December 2012, the total population of Cartagena affiliated to a system of health, subsidized or contributory, was $987.900[15,16]$. So the number of people in the city between this age ranges today is about 578.909 . Based on the study by Manzur et al. in Cartagena for 2001 in which a prevalence of high cardiovascular risk of $12.5 \%$ is inferred, the universe of the study constituted an estimated number of 72,364 patients [17]. Assuming a prevalence of $\mathrm{CKD}$ in patients at high cardiovascular risk (38\%) and taking into account the criteria of inclusion and exclusion, accepting a security level of $95 \%$ and an error rate of $5 \%$, we calculated a required sample of 653 patients [18]. All patients gave their consent to participate in the study.

The procedure for the selection of the sample began by determining the population covered by each EPS and according to the proportion, the number and characteristics of specific patients that they would provide were stipulated. Later we reviewed clinical records to verify the inclusion and exclusion criteria. Of those selected, the following data was recorded: bio-demographic data, cardiovascular risk pathology, analytical data and pharmacological treatments related to hypertension, diabetes and dyslipidemia, awareness of CKD.

Weight and height were measured with the patient barefoot, using a calibrated weight and height board. The blood pressure (BP) measurement was performed after the patient was at rest for five minutes at arm level. A calibrated sphygmomanometer (Welch Allyn, Germany) was used to measure the BP.

Of the final sample, the eGFR was determined by applying the equation of Cockcroft Gault. In the event that there wasn't a prior creatinine level registered (less than 6 months) to allow the application of the equation, this study was ordered. In patients with eGFR $<60$ $\mathrm{ml} / \mathrm{min} / \mathrm{m}^{2}$ this deterioration of filtration applying the same equation with a different sample of serum creatinine with a time difference of greater than 3 months was confirmed. In the sample defined as CKD records of a recent measurement of albuminuria were taken (less than one year old) and in case the patient didn't have obliged this parameter, it was requested for measurement.

Each of the variables were coded according to the operationalization defined in the protocol by being included in the database of Microsoft Excel 2010 for subsequent tabulation, graphing and statistical analysis using statistical software IBM SPSS Statistics 19.

\section{Definitions}

The variable predictors were consciousness and unconsciousness of CKD defined as the answer "yes" or "no" in the questionnaire item "Have you been told by your doctor if you suffer from any kidney disease, have kidney problems or your kidneys are failing (excluding stones, infections, incontinence and low back pain). Unconsciousness CKD by the health system was assessed by the lack of diagnosis of $\mathrm{CKD}$ in the clinical record by the doctor treating a patient with eGFR by CG $<60 \mathrm{ml} / \mathrm{min}$ confirmed on two occasions by creatinine levels in serum separated of greater than 3 months.

BP controlled was defined by numbers $<140 / 90 \mathrm{mmHg}$ in patients with albuminuria $<30 \mathrm{mg} / \mathrm{g}$ or $<130 / 80 \mathrm{mmHg}$ if albuminuria was $>30$ $\mathrm{mg} / \mathrm{g}$. Controlled Diabetes mellitus -DM was defined as $\mathrm{HbAlc}<7 \%$ and dyslipidemia controlled by a value of $\mathrm{LDL}<100 \mathrm{mg} / \mathrm{dl}$.

Adherence to pharmacological therapy was defined as meeting more than $80 \%$ of doses of all medicines prescribed in the cardiovascular risk program, while adherence to healthy lifestyle was defined as a patient who meets the recommendations (low-sodium diet, low sugar, low -fat, high in fruits and vegetables diet, exercise greater than $30 \mathrm{~min}$ daily) for more than 5 days a week and do not smoke.

\section{Statistical analysis}

Descriptive univariate and bivariate analysis was performed using measures of central tendency and dispersion for continuous variables 
Citation: Jorge C, Keyner T, Marco L, Jessica D, Luis P, Emilio A, et al. (2016) Chronic Kidney Disease Awareness in the Population of Moderate and High Cardiovascular Risk. J Nephrol Ther 6: 261. doi:10.4172/2161-0959.1000261

Page 3 of 7

and proportions for qualitative variables. Statistical analysis was performed using the statistical software IBM SPSS 19.

The association between the different variables in the study with the consciousness or unconsciousness of CKD was determined by chisquare test and Fisher's exact test. Confidence intervals of the differences between the proportions of the variables that showed association were reported.

\section{Results}

The study population constituted 653 patients, there was a higher proportion of women (56\%) and elderly patients (57.7\%). Much of the sample belonged to lower socioeconomic strata (86.6\%); the most prevalent cardiovascular risk factors were: hypertension (94.3\%), dyslipidemia $(84.5 \%)$, diabetes $(44.4 \%)$ and obesity $(24.2 \%)$. The prevalence of CKD was $34.8 \%$ and the overall awareness of it was $70.9 \%$ and $48.2 \%$ by the health care system and the patient respectively. Adherence to a healthy lifestyle was found in $40.4 \%$ of the population while on medication adherence was $95.1 \%$ in the sample evaluated (Table 1). The highest prevalence of CKD was found in early stages (G3a and G3b) and with lower levels of albuminuria (Figure 1).

\begin{tabular}{|c|c|}
\hline Sample N & $653(100 \%)$ \\
\hline \multicolumn{2}{|c|}{ SGSSS affiliation } \\
\hline Contributory & $349(53.4)$ \\
\hline Subsidized & $304(46.6)$ \\
\hline \multicolumn{2}{|c|}{ Cardiovascular risk } \\
\hline Moderate & $326(49.9)$ \\
\hline High & $327(50.1)$ \\
\hline \multicolumn{2}{|l|}{ Sex } \\
\hline Female & $366(56)$ \\
\hline Male & $286(43.8)$ \\
\hline \multicolumn{2}{|l|}{ Age group } \\
\hline Young & $6(0.9)$ \\
\hline Adult & $303(46.4)$ \\
\hline Elderly & $344(57.7)$ \\
\hline \multicolumn{2}{|c|}{ Socioeconomic stratum } \\
\hline 1 & $234(35.8)$ \\
\hline 2 & $196(30.0)$ \\
\hline 3 & $136(20.8)$ \\
\hline 4 & $48(7.4)$ \\
\hline 5 & $29(4.4)$ \\
\hline 6 & $10(1.5)$ \\
\hline \multicolumn{2}{|l|}{ BMI } \\
\hline Normal & $206(31.5)$ \\
\hline Underweight & $15(2.3)$ \\
\hline
\end{tabular}

\begin{tabular}{|c|c|}
\hline Overweight & $274(42.0)$ \\
\hline Obese & $158(24.2)$ \\
\hline CKD & $227(34.8)$ \\
\hline \multicolumn{2}{|l|}{ Albuminuria } \\
\hline Normal & $597(91.4)$ \\
\hline Moderately Increased & $53(8.1)$ \\
\hline Severely Increased & $3(0.5)$ \\
\hline \multicolumn{2}{|l|}{ Grade of CKD by eGFR } \\
\hline G3a & $93(14.2)$ \\
\hline G3b & $94(14.4)$ \\
\hline G4 & $33(5.1)$ \\
\hline G5 & $7(1.1)$ \\
\hline HTA & $616(94.3)$ \\
\hline - $\quad$ Controlled HTA & $445(72.2)$ \\
\hline Diabetes & $290(44.4)$ \\
\hline - Controlled diabetes & $109(37.1)$ \\
\hline Dyslipidemia & $552(84.5)$ \\
\hline - Controlled dyslipidemia & $189(34.2)$ \\
\hline \multicolumn{2}{|l|}{ Adherence } \\
\hline \multicolumn{2}{|l|}{ Healthy life style } \\
\hline Always & $186(28.5)$ \\
\hline Almost always & $78(11.9)$ \\
\hline Sometimes & $179(27.4)$ \\
\hline Rarely & $210(32.2)$ \\
\hline \multicolumn{2}{|l|}{ Pharmacotherapy } \\
\hline Always & $486(74.4)$ \\
\hline Almost always & $135(20.7)$ \\
\hline Sometimes & $29(4.4)$ \\
\hline Rarely & $3(0.5)$ \\
\hline \multicolumn{2}{|l|}{ Awareness of CKD N 227 (100\%) } \\
\hline By SGSSS & $161(70.9)$ \\
\hline By patient & $110(48.2)$ \\
\hline
\end{tabular}

Table 1: Sample Characteristics. SGSSS: System General of Security Social in Health of Colombian, BMI: Body mass index, CKD: chronic kidney disease, eGFR: estimated glomerular filtration rate by Cockcroft-Gault, HTA: hypertension Adherence: meets $>80 \%$ of the recommendations (always + almost always). 
Citation: Jorge C, Keyner T, Marco L, Jessica D, Luis P, Emilio A, et al. (2016) Chronic Kidney Disease Awareness in the Population of Moderate and High Cardiovascular Risk. J Nephrol Ther 6: 261. doi:10.4172/2161-0959.1000261

Page 4 of 7

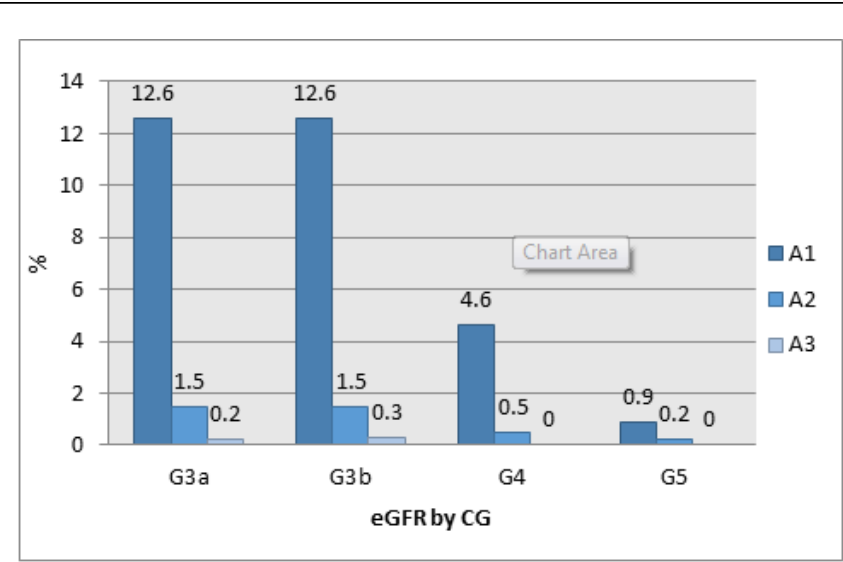

Figure 1: Prevalence of CKD by eGFR and albuminuria.

A significant association between the level of cardiovascular risk and blood pressure control ( $\mathrm{p}=0.002$ ) was found; moderate risk patients have a higher proportion of controlled patients compared to high risk (77.9\% vs. $66.6 \%$; CI $95 \%$ for the difference, 4.3 to 18.3$)$.

There was no association between the level of cardiovascular risk and control of DM $(p=0.833)$ and dyslipidemia $(p=0.706)$. Similarly no association between the level of cardiovascular risk and adherence to healthy lifestyle ( $\mathrm{p}=0.892$ ) was found (Table 2).

\begin{tabular}{|c|c|c|c|}
\hline & Moderate RCV & High RCV & $\mathbf{P}$ \\
\hline \multicolumn{4}{|c|}{ Degree of control of cardiovascular risk pathology } \\
\hline Control HTA & 77.9 & 66.6 & $p=0.002^{*}$ \\
\hline Control DM & 37.8 & 36.6 & $p=0.833$ \\
\hline Control de DL & 35 & 33.5 & $p=0.706$ \\
\hline \multicolumn{4}{|c|}{ Adherence to therapy } \\
\hline Healthy life style & 41.4 & 39.4 & $p=0.892$ \\
\hline Pharmacologic & 96 & 94.2 & $p=0.065$ \\
\hline
\end{tabular}

Table 2: Characterization of variables between moderate and high cardiovascular risk. RCV: Cardiovascular risk, HTA: arterial hypertension, DM: mellitus diabetes, DL: Dyslipidemia, System General of Security Social in Health of Colombian. BMI: Body mass index.

The results showed no association between CKD and control of hypertension $(\mathrm{p}=0.341)$, diabetes mellitus $(\mathrm{p}=0.189)$, dyslipidemia $(\mathrm{p}=0.278)$, adherence to healthy lifestyle $(\mathrm{p}=0.079)$ and adherence to medications $(\mathrm{p}=0.492)$ (Table 3$)$.

\begin{tabular}{|l|l|l|l|}
\hline \multirow{2}{*}{ Variable } & \multicolumn{2}{|l|}{ Presence of CKD } & p \\
\cline { 2 - 3 } & Yes & Not & \\
\hline Arterial hypertension & 74.5 & 71 & \multirow{2}{|l|}{$\mathrm{p}=0.341$} \\
\hline Controlled & 25.5 & 29 & \\
\hline Not controlled & 29 & \\
\hline
\end{tabular}

\begin{tabular}{|c|c|c|c|}
\hline \multicolumn{4}{|c|}{ Mellitus diabetes } \\
\hline Controlled & 42.7 & 34.6 & \multirow[t]{2}{*}{$p=0.189$} \\
\hline Not controlled & 57.3 & 65.4 & \\
\hline \multicolumn{4}{|l|}{ Dyslipidemia } \\
\hline Controlled & 37.4 & 32.7 & \multirow[t]{2}{*}{$p=0.278$} \\
\hline Not controlled & 67.3 & 62.6 & \\
\hline \multicolumn{4}{|c|}{ Healthy life style } \\
\hline Adherent & 42.7 & 39.2 & \multirow[t]{2}{*}{$p=0.079$} \\
\hline Non-adherent & 57.2 & 60.8 & \\
\hline \multicolumn{4}{|c|}{ Pharmacotherapy } \\
\hline Adherent & 95.2 & 95.1 & \multirow[t]{2}{*}{$p=0.492$} \\
\hline Non-adherent & 4.8 & 4.9 & \\
\hline
\end{tabular}

Table 3: Relationship between prevalence of CKD and cardiovascular diseases. CKD: chronic kidney disease by estimated glomerular filtration rate by Cockcroft-Gault $<60 \mathrm{~mL} / \mathrm{min} / \mathrm{m}^{2}$.

There was no association between awareness of CKD both the health system and patient and the level of cardiovascular risk (Figure 2).

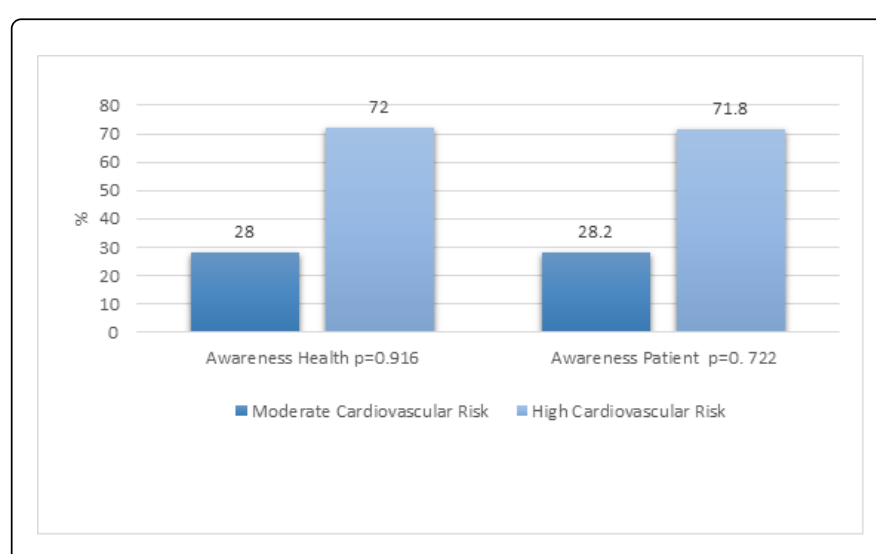

Figure 2: Relationship between awareness of CKD and cardiovascular risk by the health system and the patient.

No association between awareness of CKD patient and affiliation to the SGSSS $(p=0.392)$, level of cardiovascular risk $(p=0.916)$, age groups $(p=0.379)$, socioeconomic layer $(p=0.0901)$ was found. However there was a significant association between the patient's awareness of CKD and the gender $(p=0.009)$; in patients unaware of having CKD there is a higher proportion of women compared with those patients aware of having CKD (66.1\% vs. $49.1 \%$; $95 \%$ CI for the difference, 4.3 to 29.7) (Table 4).

\begin{tabular}{|l|l|l|l|}
\hline Variable & \multicolumn{2}{|l|}{ CKD awareness (\%) } & $p$ \\
\hline & YES & NOT & \\
\hline SGSSS affiliation & & & \\
\hline Contributory & 58.2 & 52.5 & 0.392 \\
\hline
\end{tabular}




\begin{tabular}{|l|l|l|l|}
\hline Subsidized & 41.8 & 47.5 & 0.392 \\
\hline Sex & & & \\
\hline Female & 49.1 & 66.1 & $0.009^{*}$ \\
\hline Male & 50.9 & 33.9 & $0.009^{*}$ \\
\hline Age group & & & \\
\hline Young & 0 & 0.8 & 0.379 \\
\hline Adult & 13.6 & 9.3 & 0.379 \\
\hline Elderly & 86.4 & 89.8 & 0.379 \\
\hline $\begin{array}{l}\text { Socioeconomic } \\
\text { stratum }\end{array}$ & & & \\
\hline 1 & 39.1 & 36.4 & 0.09 \\
\hline 2 & 29.1 & 33.1 & 0.09 \\
\hline 3 & 20 & 18.6 & 0.09 \\
\hline 4 & 4.5 & 6.8 & 0.09 \\
\hline 5 & 4.5 & 2.5 & 0.09 \\
\hline 6 & 2.7 & 2.5 & 0.09 \\
\hline Healthy life style & 35.5 & 77.1 & $<0.0001^{*}$ \\
\hline Adherent & & & \\
\hline Non-adherent & 98.2 & 92.4 & $0.041^{*}$ \\
\hline Pharmacotherapy & 7.6 & & \\
\hline Adherent & & & \\
\hline Non-adherent & & & \\
\hline
\end{tabular}

Table 4: Relationship between variables and patient awareness of CKD. SGSSS: System General of Security Social in Health of Colombian, Socioeconomic Stratum: Classifications of social class in Colombia taking into account their income and social conditions, Adherence: The patient meets $>80 \%$ of their medication and medical indications.

A significant association between awareness of CKD and adherence to lifestyle $(\mathrm{p}<0.0001)$ was shown; patients unaware of having CKD have lower adherence to healthy lifestyle than patients with awareness of CKD (22.9\% vs. $64.5 \%$; $95 \%$ CI for the difference, 29.9 to 53.3$)$. A significant association between awareness of CKD and medication adherence $(\mathrm{p}=0.041)$ was found, showing that unconscious patients have a lower proportion of medication adhesion than conscious CKD patients (92.4\% vs. 98.2\%; 95\% CI for the difference, 2.7 to 11.3) (Table $4)$.

There was a significant association between CKD awareness by the patient and the degree of CKD $(p<0.0001)$; to compare unaware CKD patients with aware CKD patients, a greater proportion of patients met CKD G3a (56.8\% vs. $23.9 \%$; $95 \%$ CI for the difference, 20.9 to 44.9 ), and lower CKD G3b ratio (34.7\% vs. $48.6 \%$; $95 \%$ CI for the difference, 11.8 to 26.6 ), CKD G4 (8.5\% vs. $21.1 \%$; $95 \%$ CI for the difference, 3.4 to 21.8 ) and CKD G5 (0\% vs. $6.4 \%$; $95 \%$ CI for the difference, 1.8 a11) (Figure 3). CKD unconscious patients have a significantly lower overall proportion of patients with CKD G3b, G4 and G5 (moderate to advanced CKD) compared to patients aware of CKD (43.2 vs. $76.1 \%$;

95\% CI for the difference, 20.9 to $44.9 ; \mathrm{p}<0.00001)$. CKD unconscious patients have a significantly higher proportion of patients with CKD G3a (mild) compared to patients aware of CKD (56.8\% vs. $23.9 \%$; $95 \%$ CI for the difference, 20.0 to $44.9 ; \mathrm{p}<0.00001$ ).

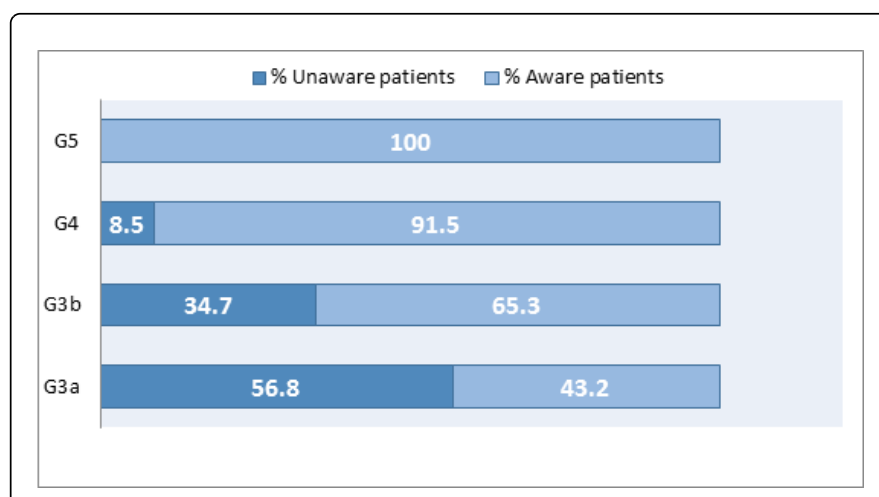

Figure 3: Relationship between the degree of CKD and awareness of it.

\section{Discussion}

This study demonstrates the high prevalence of CKD in the population with cardiovascular risk (34.8\%), comparable to that of similar studies conducted in this population (37.3\%), however diagnosis rates by the health system are still low (70.9\%), which can lead to the lack of use of the formulas needed to calculate the eGFR, since most of undiagnosed patients were in stage G3a (56.8\%), where the value of isolated creatinine is almost certainly in ranges expressed as "normal", allowing under diagnosis especially in women and elders which covers most of our population [18-20].

It is noteworthy the degree of awareness of CKD by the patients (48.2\%), which although still low, is higher than the ones published elsewhere (6-23\%) [11,12,19,21,22]. We considered as a possible factor that most of our patients had diabetes or hypertension, comorbid conditions that have shown increased conscience because of their higher risk assessment and recognition of CKD associated with better care by trained staff $[11,19]$.

It's worth to highlight the difference in awareness of CKD according to the degree of deterioration of eGFR in an inversely proportional and statistically significant way, demonstrating in our work a higher rate of consciousness in patients with CKD G4 and G5 (Figure 3) compared to the G3a stage ( $91.5 \%-100 \%$ vs. $43.2 \%$ ), this has also been determined in other populations where the consciousness is better at lower eGFR $[11,19,21,23]$. This increased awareness can be explained due to the fact that generally these patients are exposed to better programs and specialized health personnel in the care of their comorbidities, as determined in the last guide the ministry of social protection, indicating that patients with advanced CKD should be handled by specialists in nephrology which would imply tracking patients in programs that provide the opportunity of a greater awareness of their condition [24].

In regard to the lower degree of awareness of CKD by the female population evaluated ( $33.9 \%$ vs. $50.9 \%$ ), these data are consistent with those reported in other populations where a greater awareness of CKD is shown in men, which may be due to their higher levels of creatinine in which doctors less familiar with CKD could easily recognize them as 
Page 6 of 7

CKD patients $[11,12,19,25]$. Moreover many professionals have the perception of a lower risk of CKD in women compared to its counterpart, men. In addition, much of the symptoms of CKD in women tend to be most likely attributed to other causes.

Control rates of hypertension reported in the general population vary from $5.4 \%-58 \%$ [26]. In our study the prevalence of controlled hypertensive patients was significantly better (72.2\%) which are somewhat higher than those reported in the register the program of hypertension for 2011 in Colombia (60.2\%), probably due to the high adherence to pharmacologic management greater than 95\%, in contrast to the publications in other populations with default rates and higher treatment withdrawal $(47-57 \%)[23,25,27]$. With regard to the significant difference found in the degree of control in patients with moderate cardiovascular risk compared with those at high risk, it is probably due to the scale used to catalog the cardiovascular risk of patients where a patient with hypertension controlled most likely was assigned to a lower risk level. Otherwise represents control diabetes and dyslipidemia (represented by HbAlc $<7 \%$ and $\mathrm{LDL}<100 \mathrm{mg} / \mathrm{dL}$ ) which was achieved in only $44.4 \%$ and $34.2 \%$ respectively of the population studied, slightly inferior to other studies (50\%) rates; this may reflect a lack of adherence to non-pharmacological measures (healthy lifestyle), compliance and control are essential for the proper management of these patients; non-adherence is associated with a high rate overweight and obesity (66.2\%) [28].

A relevant point determined in our work and that had already been suggested in another study is the relationship between consciousness of CKD and adherence to management, showing the difference in conscious patients with CKD compared with unaware ones regarding the adherence of healthy life habits (low- sodium diet, low sugar, lowfat, exercise 150 min weekly and smoking cessation), being the conscious patients of having CKD much more adherents $(64.5 \%$ vs. $22.9 \%$ ) [21]. Moreover it also determined a statistically significant difference towards achieving drug therapy in the population aware of CKD (98.2\% vs. 92.4\%), which has demonstrated in other trials improvement in the control of cardiovascular risk pathologies [29]. This relationship encourages the promotion of education programs aimed at the health system actors and patients treated in it, (mainly those at high risk for the disease) in raising awareness of this disease [30].

Within the limitations of our trial we found that the question to define awareness CKD was not previously validated in our country, however this same question has been used to define consciousness of CKD in different populations by what we consider acceptable for our population [12,19]. Moreover, the serum creatinine level used for calculating eGFR, was determined in the laboratory of each EPS, so that the methods for testing are probably not homogeneous. However, this situation reveals the real conditions for the diagnosis, classification and management of CKD in this population. Similarly the formula used to calculate eGFR was the Cockcroft-Gault, which has demonstrated in the light of current evidence to be less accurate than their newer counterparts (MDRD and CKD -EPI) [8]. However, in our country the data in the national registry to account of high cost for CKD are based on eGFR by use of this formula [7]. One of the strengths of our study was that the limitation of the transverse studies previously published of not allowing distinguishing the patients with CKD of those with transitory alteration of the eGFR was erased.

\section{Conclusions}

This study demonstrates the high prevalence of CKD in patients with moderate and high cardiovascular risk, highlighting the low awareness people have of the same both for the patient and the care staff caring for this population.

Our trial emphasizes the need to improve the knowledge and training of personnel attending this pathology in cardiovascular risk programs, with the active collaboration of kidney health programs, because although this is a political and financial challenge in countries like ours, it should not underestimate the importance of increasing awareness of the CKD considering that cannot only result in slowing the progression to the terminal stage of the disease with the dependence on dialysis and transplantation, but can also affect in reducing cardiovascular morbidity and mortality to be an independent risk factor, thus achieving an impact on the Colombian economy, considering that the cost is higher than for any other disease.

\section{References}

1. (2011 )World Health Organization. Causes of death 2008: data sources and methods.

2. William GC, Giuseppe R, Shanthi M, Marcello T (2011) The contribution of chronic kidney disease to the global burden of major noncommunicable diseases. Kidney Int 80: 1258-1270.

3. Ritz E (2010) Cardiovascular disease in patients with chronic kidney disease-An update. Hipertens riesgo vasc 27: 75-79.

4. (2012) Organización Mundial de la Salud. Estadísticas Sanitarias Mundiales.

5. D'Agostino RB, Vasan RS, Pencina PJ, Wolf PA, Cobain M, et al. (2008) General Cardiovascular Risk Profile for Use in Primary Care : The Framingham Heart. Circulation 117: 743-753.

6. Kdigo (2012) Clinical Practice Guideline for the Evaluation and Management of Chronic Kidney Disease. Kidney International Supplements 3:19-62.

7. (2014) Colombian Fund High Cost Disease. Situation of chronic kidney disease in Colombia Resolution.

8. Earley A, Miskulin D, Lamb EJ, Levey AS, Uhlig K (2012) Estimating equations for glomerular filtration rate in the era of creatinine standardization: a systematic review. Ann Intern Med 156: 785-795.

9. Poggio ED, Wang X, Greene T, Van Lente F, Hall PM (2005) Performance of the Modification of Diet in Renal Disease and Cockcroft-Gault Equations in the Estimation of GFR in Health and in Chronic Kidney Disease. J Am Soc Nephro. 16: 459-466.

10. Herzog CA, Asinger RW, Berger AK, Charytan DM, Díez J, et al. (2011) Cardiovascular disease in chronic kidney disease. A clinical update from Kidney Disease: Improving Global Outcomes (KDIGO). Kidney Int. 80: 572-586.

11. Plantinga LC, Boulware LE, Coresh J, Stevens LA, Miller ER, et al. (2008) Patient awareness of chronic kidney disease: trends and predictors. Arch Intern Med. 168: 2268-2275.

12. Coresh J, Byrd-Holt D, Astor BC, Briggs JP, Eggers PW, et al. (2005) Chronic kidney disease awareness, prevalence, and trends among U.S. adults, 1999 to 2000. J Am Soc Nephrol. 16: 180-188.

13. Roderick PJ (2012) Chronic kidney disease in older people: a cause for concern? Nephrol Dial Transplant 27: 1-4.

14. Obrador GT, García-García G, Villa AR, Rubilar X, Olvera N, et al. (2010) Prevalence of chronic kidney disease in the Kidney Early Evaluation Program (KEEP) Mexico and comparison with KEEP US. Kidney Int Suppl 116: S2-S8.

15. Aguilera M, Meisel A (2009) Working papers on regional economy. Is the island that is repeated? Cartagena on Census 2005 population of the Central Bank Republic of economic and regional studies (CEER) Cartagena 109: 1-47. 
Citation: Jorge C, Keyner T, Marco L, Jessica D, Luis P, Emilio A, et al. (2016) Chronic Kidney Disease Awareness in the Population of Moderate and High Cardiovascular Risk. J Nephrol Ther 6: 261. doi:10.4172/2161-0959.1000261

Page 7 of 7

16. (2012) Administrative District Health Department (DAD). Insured population statistics.

17. Manzur F, Arrieta C, Tapia C (2001) Risk factors, incidence and prevalence of cardiovascular disease in a population between 25 and 70 years in the city of Cartagena de Indias (Bolívar).RCC 8: 363-368.

18. Cases A, González-Juanatey JR, Conthe P, Matali A y Garrido C. Prevalence of chronic renal failure in patients at high risk or with cardiovascular disease. Rev Esp Cardiol 63: 225-228.

19. Hsu CC, Hwang SJ, Wen CP, Chang HY, Chen T, et al. (2006) High prevalence and low awareness of CKD in Taiwan: a study on the relationship between serum creatinine and awareness from a nationally representative survey. Am J Kidney Dis 48: 727-738.

20. Perrone RD, Madias NE, Levey AS (1992) Serum creatinine as an index of renal funtion: New insights, into old concepts. Clin Chem 38: 1933-1953.

21. Tuot DS, Plantinga LC, Judd SE, Muntner P, Hsu CY, et al. (2013) Healthy Behaviors, risk factor control and awareness of chronic kidney disease. Am J Nephrol 37: 135-143.

22. Shah A, Fried LF, Chen SC, Qiu Y, Li S, et al. (2012) Associations Between Access to Care and Awareness of CKD. Am J Kidney Dis 59: S16-S23.

23. Doumas M, Tsioufis C, Faselis C, Lazaridis A, Grassos H, et al. (2014) Non-interventional management of resistant hypertension. World J Cardiol 26: 1080-1090.
24. (2005) Ministry of social protection. Management Guide To Chronic kidney disease based on evidence. Colombia. Foundation for research and development of health and social security.

25. (2014) Ministry of Health and Social-Information System for Quality Protection. Registration Hypertension Program (IPS Report).

26. Kearney PM, Whelton M, Reynolds K, Whelton PK, He J (2004) Worldwide prevalence of hypertension: a systematic review. J Hypertension 22: 11-19.

27. Corrao G, Zambon A, Parodi A, Poluzzi E, Baldi I, et al. (2008) Discontinuation of and changes in drug therapy for hypertension among newly-treated patients: a population-based study in Italy. J Hypertens 26 : $819-824$

28. (2011) Metabolic Control in Type 2 diabetic patients: degree of control and level of knowledge (Azuer Study).Rev Clin Med Fam. 4: 32-41.

29. Ravera M, Noberasco G, Weiss U, Re M, Gallina AM, et al. (2011) CKD Awareness and Blood Pressure Control in the Primary Care Hypertensive Population. Am J of Kidney Dis 57: 71-77.

30. Hsiao L, Wu J, Yeh, A, Shieh, Cui C, et al. (2014) Kidney Disease Screening and Awareness Program (KDSAP): A Model for Potentially Increasing the Nephrology Workforce. J Am Soc Nephrol 25: 1909-1915. 